\title{
INVESTIGANDO ARGUMENTAÇÃO E TOMADA DE DECISÃO NO ENSINO SUPERIOR DE GENÉTICA: A QUESTÃO SOCIOCIENTÍFICA DO USO DE MARCADORES MOLECULARES PARA CÂNCER
}

\author{
$\underline{\text { Karine Brandão Oliveira Rios }} \mathbf{1}$; Susie Vieira de Oliveira²; Claudia de Alencar \\ Serra e Sepulveda ${ }^{3}$ \\ 1. Bolsista PIBIC/FAPESB, Graduanda em Ciências Biológicas, Universidade Estadual de Feira de Santana, \\ e-mail: Karine.bor@hotmail.com \\ 2. Orientadora, Departamento de Ciências Biológicas, Universidade Estadual de Feira de Santana, e-mail: \\ susie_vieira@terra.com.br \\ 3. Coorientadora, Departamento de Educação, Universidade Estadual de Feira de Santana, e-mail: \\ causepulveda@ig.com.br
}

PALAVRAS-CHAVE: Câncer, Questões Sociocientíficas, Argumentação.

\section{INTRODUÇÃO}

Dentre as doenças humanas de natureza multifatorial, o câncer ocupa lugar de destaque, pela sua importância médica, social e econômica (Frank, 2007, Kumar et al., 2010). Estudos que buscam o conhecimento do comportamento biológico de neoplasias tem como objetivo principal a identificação das diversas moléculas que atuam neste processo e o uso potencial destas como marcadores moleculares da doença. Tais marcadores devem ser capazes de informar sobre o diagnóstico precoce, origem, extensão da lesão, ou ainda, sobre o prognóstico e a resposta terapêutica (Frank, 2007, Hurst, R.E., 2009, Calzone, 2012).

No entanto, na medida em que novos estudos vem sendo desenvolvidos, está ficando claro que nenhum marcador isolado tem potencial informacional suficiente para o uso clínico inequívoco ou para predição do risco individual de desenvolvimento do câncer. Mesmo ao usar painéis de marcadores múltiplos, são muitas as limitações dessas análises quando se trata de usá-los como testes genéticos de susceptibilidade ao desenvolvimento neoplásico (AbuAsab et al., 2011, Chung; Chanock, 2011). Apesar disso, muitas destas moléculas já são comercializadas como testes genéticos preditivos de susceptibilidade ao câncer, o que já tem causado impacto emocional e social (Calzone et al., 2008, Calzone, 2012, Belyea, 2011).

Pelas razões explicitadas acima, e pelo fato do ensino de genética vir sendo apontado como uma necessidade na formação de jovens conscientes e capazes de tomar decisões em relação à sua própria vida (Barni, 2010) e, em vista da importância da genética para a alfabetização científica dos estudantes, entende-se que é necessário discutir, com alunos de licenciatura em Ciências Biológicas, amplamente as questões sociais e científicas envolvidas no desenvolvimento de marcadores moleculares para doenças humanas, utilizando, para isso, o uso da abordagem Ciência/Tecnologia/Sociedade (CTS) para promover o desenvolvimento das habilidades de tomar decisões, reconhecer alternativas, aplicar informações e selecionar opções relativas à saúde em nível comunitário e pessoal (Calzone et al., 2011, Belyea, 2011).

Nesse trabalho adotamos a proposição de que a abordagem de questões sociocientíficas propiciam o desenvolvimento de argumentação, e que o uso de estratégias baseadas em atividades de júri simulado em QSC em cursos de formação inicial de professores potencializa o desenvolvimento de habilidades argumentativas por parte desses profissionais, dessa maneira, visou-se a construção e investigação de uma sequência didática sobre determinismo genético e uso socialmente responsável de marcadores moleculares para o câncer a partir da análise da argumentação nas discussões em sala de aula desse tema com alunos do ensino superior do curso de Licenciatura em Ciências Biológicas, que cursaram a disciplina Genética Básica.

Desta maneira, o presente trabalho pretendeu responder a seguinte questão de pesquisa: "Quais são as características de uma sequência didática baseada em uma atividade 
de júri simulado em QSC sobre o uso de marcadores moleculares para o câncer para discutir as controvérsias e implicações sociais do uso desses marcadores para essa doença em uma turma de Licenciatura em Ciências Biológicas cursando a disciplina Genética Básica?"”

\section{METODOLOGIA}

Trata-se de uma pesquisa de desenvolvimento baseada na design research, entendida como o estudo sistemático do planejamento, da implementação, da avaliação e da manutenção de intervenções educacionais inovadoras, visando a busca de soluções para problemas da prática educacional, através da elaboração de princípios de planejamento de inovações didáticas que possam ser aplicáveis, mediante adaptações, a vários contextos (BAUMGARTNER et al. 2003; PLOMP, 2009).

Esse processo investigativo da design research pode ser descrito, de modo geral, em termos da realização cíclica de três fases: pesquisa preliminar, fase de prototipagem e fase avaliativa (TARDIF). O presente trabalho encontra-se na segunda fase de investigação, segundo a perspectiva de Plomp (2009), onde inicialmente foi realizada uma revisão da literatura sobre câncer e marcadores moleculares genéticos, identificando os problemas relativos ao ensino desses conteúdos, provendo dessa maneira uma estrutura conceitual à pesquisa, avançando até o primeiro momento da prototipagem que foi o desenvolvimento dos princípios de design ou de planejamento, que orientaram a elaboração de um protótipo de intervenção pedagógica (construção de uma sequência didática).

\section{RESULTADOS E DISCUSSÃO}

Como resultados da fase preliminar são apresentados os princípios de design que resultaram da pesquisa de literatura nos campos: (1) Herança multifatorial; (2) Câncer; (3) marcadores Moleculares; (4) Educação CTS e uso de questões sociocientíficas e (5) Argumentação no Ensino de ciências. Além dos princípios de design, consideramos como resultado o primeiro protótipo de uma sequência didática. E, enquanto resultado da segunda fase desse estudo, é apresentada a análise dos argumentos dos alunos durante a sequência didática, segundo o padrão de Toulmin (1958).

Entretanto, aqui será apresentado apenas o caso investigativo que norteou o júri simulado (Figura 1) e um argumento de um aluno ao longo do júri simulado dentro da estrutura do padrão de argumento segundo Toulmin, evidenciando os elementos do argumento que foram identificados na fala do estudante em questão (Diagrama 1).

\section{Diagrama 1:}

$$
\text { ADVOGADA DE DEFESA } 2 \text { (AD2) - ARGUMENTO } 1
$$

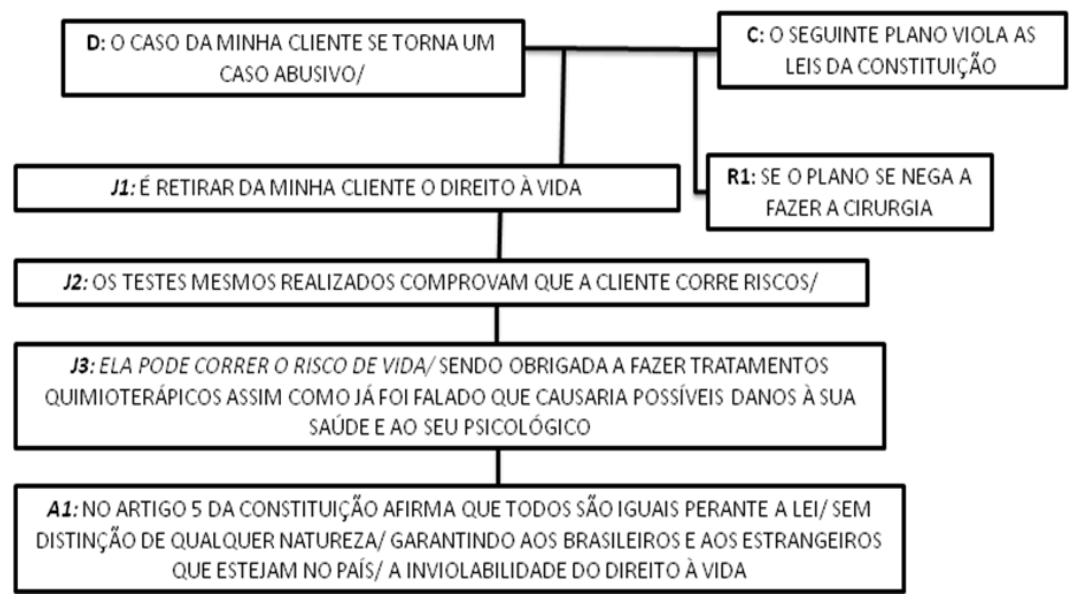


A engenheira Susana Brasil, de 39 anos, realizou um exame genético, pago por conta própria, que apontou que ela tinha $87 \%$ de chances de ter câncer de mama. Ela decidiu se submeter a cirurgia da dupla mastectomia preventiva, entretanto o plano de saúde o qual ela era associada recusava realizar o pagamento das despesas dessa cirurgia, alegando que não era de cobertura obrigatória, pois a paciente não possuía nenhum diagnóstico clínico da doença, e que por essa razão esse procedimento não era de cobertura obrigatória

Diante dessa situação a engenheira foi à justiça em busca de seus direitos. O juiz enviou uma convocação aos empresários representantes do plano de saúde e à Susana, para comparecerem diante do tribunal para resolver esta situação.

Vocês, alunos da turma de Genética Básica, irão representar essa situação em um júri simulado e deverão tomar uma decisão para solucionar esse caso. Para tanto, durante a preparação desse júri simulado, deverão ser mobilizadas as seguintes questões:

1) O resultado positivo de determinado marcador genético é necessário e suficiente para o desenvolvimento de câncer?

2) Uma vez detectada a positividade do marcador genético positivo, o plano terá obrigatoriedade de arcar com as cirurgias preventivas?

3) Outros parâmetros deverão ser considerados para estimar a real possibilidade do individuo desenvolver a doença?

Figura 1. Caso investigativo: sequenciamento genético e mastectomia preventiva.

Analisando os argumentos dos alunos ao longo do júri simulado identificou-se que os alunos que representaram os advogados de defesa apresentam mais justificativas e apoios em seus argumentos que os alunos que representaram os advogados de acusação, indicando que a qualidade desses argumentos é maior, visto que, várias pesquisas utilizam a quantidade de justificativas oferecidas em cada argumento como um dos fatores de qualidade de um argumento (MEANS; VOSS, 1996; SADLER; FOWLER, 2006; PENHA, 2012).

Enquanto a análise da natureza desses argumentos, é possível perceber que os alunos utilizaram de justificativas legais/jurídicas, sociais e da saúde do que justificativas científicas/biológicas em seus argumentos. Além disso, quando os mesmos utilizaram de justificativas científicas cometeram alguns erros conceituais, como apresentar um câncer hereditário como sendo equivalente a um câncer genético.

Apesar da maior qualidade dos argumentos dos advogados de defesa à Susana, na decisão final os jurados apoiaram o plano de saúde e apresentaram maior qualidade em seu argumento, maior quantidade de justificativas, e a natureza de seus argumentos foi científica. Já os jurados de defesa da engenheira Susana apresentaram um argumento de natureza moral e legal, quando apresentam em suas justificativas expressões como: "o direito a escolha" $e o$ "direito a decidir sobre seu corpo". Isso demonstra que o caso investigativo cumpriu o seu papel de fomentar a discussão de assuntos de natureza científica e sociocientífica a partir da questão nele embutida: o uso de marcadores moleculares para a determinação do câncer.

\section{CONSIDERAÇÕES FINAIS}

Os resultados dessa pesquisa permitem concluir o potencial heurístico tanto da sequência didática em questão, quanto dos princípios de design elencados como base norteadora para que os objetivos de ensino sejam alcançados, tendo em vista que, a literatura aponta a necessidade de ser desenvolvida nas escolas uma educação que estimule o senso crítico dos estudantes, bem como o entendimento de seu papel como cidadão e portanto 
agente transformador da realidade na qual está inserido e para isso é necessário que o professor esteja apto para exercer este papel de enquanto mediador e promotor desse desenvolvimento do senso crítico e que possua estratégias metodológicas que lhe permitam alcançar estes objetivos.

Portanto, entende-se que a sequência didática apresentada, bem como os princípios de design, fazem parte de um esforço que se preocupa em estimular um ensino de ciências mais crítico, aproximando os estudantes de licenciatura em Ciências Biológicas de questões referentes à natureza do conhecimento científico bem como relacionar questões científicas à âmbitos referentes à implicações políticas, éticas e morais que estão relacionadas à ciência.

\section{REFERÊNCIAS}

ABU-ASAB, M.S. et al. Biomarkers in the Age of Omics: Time for a Systems Biology Approach. OMICS. 15(3): 105-112. 2011.

BAUMGARTNER, E., BELL, P., BOPHY, S. ET AL. Design-based research: An emerging paradigm for educational inquiry. Educational Researcher, 32, 5-8, 2003.

BARNI, G. dos S. A Importância e o Sentido de Estudar Genética para Estudantes do Terceiro Ano do Ensino Médio em uma Escola da Rede Estadual de Ensino em Gaspar (SC); 2010. <www.sed.sc.gov.br/secretaria/.../doc.../2326-graziela-dos-santos-barni>

BELYEA, R. Genetic testing for common cancer genes. Journal of Medical Imaging and Radiation Sciences, v. 42, p. 137-144, 2011.

CALZONE, K.A. Genetic biomarkers of cancer risk. Seminars in Oncology Nursing, v. 28, n. 2, p. 122-128, 2012.

CALZONE, K.A., SOBALlE, P.W. Genetic testing for cancer susceptibility. Surg. Clin. N. Am., v. 88, p. 705-721, 2008.

CHUNG, C.C., CHANOCK, S.J. Current status of genome-wide association studies in cancer. Hum. Genet., 130: 59-78, 2011.

FRANK, S.A.Dynamics of Cancer: Incidence, Inheritance, and Evolution. New Jersey: Princeton University Press. 2007

HURST, R.E. Does the biomarker search paradigm need re-booting? BMC Urology, 9: 1-3, 2009.

KUMAR, V. ET AL. ROBBINS AND COTRAN - Pathologic Basis of disease. Philadelphia: Saunders Elsevier. $8^{\text {th }}$ Ed. 2010.

MEANS, M. L; VOSS, J. F. Who reasons well? Two studies of informal reasoning among children of different grade, ability, and knowledge levels. Cognition and Instruction, 14, 139$178,1996$.

PENHA, S. P. da. Atividade sociocientífica em sala de aula de física: as argumentações dos estudantes. - São Paulo, 2012. In: Tese (Doutorado) - Universidade de São Paulo. Faculdade de Educação, Instituto de Biociências, Instituto de Física e Instituto de Química. 2012.

PLOMP, T. Educational Design Research: an Introduction. In: PLOMP, T. NIEVEEN. N.An introduction to educational Design Research,. Enschede: SLO-Netherlands Institute for Curriculum Development. pp. 9-35. 2009.

SADLER, T. D; FOWLER, S. R. A threshold model of content knowledge transfer for socioscientific argumentation. Science education, v. 90, n. 6, pp. 986-1004. 2006

TOULMIN, S. (1958/2006). Os Usos do Argumento. Trad. Reinaldo Guarany. São Paulo: Martins Fontes.

TARDIF, M.Saberes docentes e formação profissional. Petrópolis:Vozes, 8ª̃d. 2007. 